\title{
APLIKASI BAHASA ISYARAT SEDERHANA BERBASIS ANDROID
}

\author{
Ruly S. Sinukun ${ }^{*}$ ) \\ Program Studi Teknik Informatika, Politeknik Gorontalo
}

\begin{abstract}
ABSTRAK-Bahasa isyarat merupakan penghubung untuk berinteraksi dengan orang lain dalam kehidupan sehari-hari seperti Di kampus Politeknik Gorontalo, sekarang ini masih menggunakan bahasa isyarat dengan mengunakan terjemahan bahasa isyarat.

Bahasa isyarat merupakan salah satu cara untuk berkomunikasi secara langsung sesama penyandang tunarungu dan tunawicara atau dengan orang lain mengunakan gerakan tangan dengan eksperesi wajah atau tubuh. Untuk itu di bangunlah sebuah system aplikasi bahasa isyarat.

Aplikasi ini sangat memudahkan bagi yang belum mengetahui gerakan bahasa isyarat. Aplikasi ini menggunakan pemrograman android dengan desain menggunakan photoshop beserta Eclipse dan Java berserta ADT Bundle untuk sebagai pendukung eclipse.

Dengan adanya aplikasi bahasa isyarat dan dapat mudah di mengerti gerakan bahasa isyarat.
\end{abstract}

Kata kunci: android, Bahasa Isyarat, Eclipse, java, ADT, Bundle.

\section{PENDAHULUAN}

Bahasa merupakan penghubung untuk berinteraksi dengan orang lain dalam kehidupan sehari-hari seperti sekarang ini, ada bahasa yang digunakan oleh masyarakat luas yang salah satunya adalah bahasa isyarat. Bahasa isyarat adalah bahasa yang digunakan oleh individu yang memiliki keterbatasan dalam berkomunikasi dengan masyarakat di dalam kehidupan sehari-harinya.

Bahasa isyarat merupakan salah satu cara untuk berkomunikasi secara individual sesama penyandang tunarungu dan tunawicara atau dengan orang lain. Bentuk bahasa isyarat mengenai sistematis tentang seperangkat isyarat jari tangan, dan berbagai bentuk cara untuk melambangkan gerakan isyarat sebagai kosa kata dalam bentuk bahasa indonesia.

Merupakan individu yang memiliki keterbatasan fisik atau mental/intelektual. Tunarungu dan tunawicara adalah sekelompok orang yang menggunakan bahasa isyarat dalam bentuk gerakan anggota tubuh, biasanya mengunakan bentuk gerakan tangan atau lengan, serta ekspresi wajah yang di lakukan untuk mengungkapkan pikiran. Sedangkan merupakan individu yang sering mengalami kesulitan dalam berkomunikasi.

Individual yang mengalami gangguan terkhusus penderita tunarungu dan tunawicara pada dasarnya adalah manusia yang butuh beradaptasi dengan lingkungan sekitar. Keterbatasan yang mereka miliki membuat adanya sekat dengan orang lain karena susah untuk memahami

\author{
Yusman Darise ${ }^{2}$ ) \\ Program Studi Teknik Informatika, Politeknik Gorontalo \\ 60111, email : yusmandarise96@gmail.com
}

bahasanya, contoh kasus ketika bahasa isyarat ingin melanjutkan pendidikan setelah jenjang setelah SLB (Sekolah Luar Biasa), tentunya mereka memerlukan kampus khusus untuk penderita disabilitas, yang pada kenyataanya kampus untuk penderita disabilitas masih terbatas. Hal ini yang membuat sumber daya yang mereka miliki tidak berkembang.

Dengan adanya kasus tersebut penulis membuat sebuah bahasa isyarat bagi penyandang disabilitas yang di implementasikan pada perangkat Ponsel yaitu android. Penulis memilih android sebagai media implementasi dari bahasa isyarat tersebut karena Android merupakan sebuah system operasi Ponsel yang memiliki banyak kemudahan dilihat dari segi ekonomi, fasilitas dan kenyamanan pengguna. Bahasa isyarat yang akan penulis buat merupakan pengembangan dari bahasa isyarat yang berbentuk buku.

\section{Rumusan Masalah}

Bagaimana komunikasi yang dilakukan oleh penyandang disabilitas tunarungu dan tunawicara sehingga dapat dipahami oleh masyarakat.

\section{Batasan Masalah}

Aplikasi ini digunakan untuk orang yang belum mengetahui bahasa isyarat tunarungu dan tunawicara. Menjadi batasan masalah dalam penelitian ini adalah:

1. Penelitian ini dilakukan di lingkungan Politeknik Gorontalo

2. Apalikasi ini hanya mengunakan 80 kata yang ada didalam aplikasi

3. Aplikasi bahasa isyarat ini bisa digunakan di Ponsel Android.

\section{Tujuan}

Tujuan dari penelitian ini adalah membangun sebuah aplikasi bahasa isyarat bagi tunarungu dan tunawicara agar mampu untuk berkomunikasi dengan masyarat dan juga sebagai media bagi pembelajaran untuk berdiskusi dengan tunarungu.

\section{Manfaat}

Manfaatnya dari penelitian ini agar berkomunikasi dalam bentuk bahasa isyarat antara tunarungu dan tunawicara.

\section{LANDASAN TEORI}

Android adalah system operasi berbasis linux yang digunakan untuk telepon seluler (mobile) seperti telpon pintar (smartphone) dan personal digital Assitant (PDA). 
Android menyediakan platfom terbuka bagi para pengembang untuk menciptakan aplikasi mereka sendiri yang diguanakan oleh bermacam piranti bergerak. Android kini menjadi system operasi mobile terpopuler di dunia. Perkembangan android tidak lepas dari peran Google (Pratama 2011).

\section{Android Honeycomb (Versi 3.0/ 3.1)}

Honeycomb adalah sereal manis yang populer sejak tahun 1965, berupa sereal jagung dengan rasa madu yang berbentuk sarang lebah. Honeycomb dirilis pada Februari 2011, kemudian disusul dengan cepat pada versi 3.1 dan 3.2. Android versi ini khusus dan benar-benar dioptimalkan untuk tablet. Android versi ini mendukung ukuran layar yang lebih besar. User Interface pada Honeycomb juga berbeda karena sudah didesain untuk tablet. Honeycomb juga mendukung multi prosesor dan juga akselerasi perangkat keras (hardware) untuk grafis. Tablet pertama yang dibuat dengan menjalankan Honeycomb adalah Motorola Xoom. Perangkat tablet dengan platform Android 3.0 akan segera hadir di Indonesia. Perangkat tersebut bernama Eee Pad Transformer produksi dari Asus. Android Honeycomb ini telah mulai memasuki pasar Indonesia sejak Mei 2011.

\section{Android Jelly Bean (Versi 4.1)}

Android 4.1 Jelly Bean diumumkan pada 27 Juni 2012 pada konferensi Google l/O. Versi ini adalah yang tercepat dan terhalus dari semua versi Android. Jelly Bean 4.1 meningkatkan kemudahan dan keindahan tampilan dari Ice Cream Sandwich dan memperkenalkan pengalaman pencarian Google yang baru di Android. Android Jelly Bean lebih fiturnya ke peningkatan User Interface yanga lebih lancar dan responsif. Di versi ini juga menandai hadirnya fitur Google Now yang memberikan saran dan rekomendasi berdasarkan data-data yang tersimpan (kontak, kalender, lokasi, dll) di Handphone.

Android Jelly Bean dirancang untuk meningkatkan performa dari perangkat elektronik yang menggunakan sistem operasi ini. Hal ini terbukti dari meningkatnya kecepatan dan respon dari perangkat terhadap perintah pengguna tanpa adanya lag pada saat transisi tampilan dari aplikasi yang satu ke aplikasi yang lain. Hal ini karena Google telah mengembangkan lebih optimal terhadap optimalisasi prosesor untuk meningkatkan responsifitas smartphone atau tablet. Apabila kita masih menggunakan Android versi yang lama disarankan untuk mengupgrade ke Android versi Jelly Bean.

\section{Java Development Kit (JDK)}

Java adalah pemrograman yang sudah ada sejak dikalangan para komputer. Java pertama kali sudah dilakukan untuk kebutuhan akan sebuah bahasa komputer yang ditulis sejak pertamakali dan dapat bisa dapat dijalankan dengan system komputer berbeda. Pada umumnya, para prefisional berpendapat bahwa bahasa Java memiliki konsep sistem pemrograman objek dan aman untuk digunakan.Java sekarang ini masih merupakan bahasa pemrograman yang masih digemari dan banyak digunakan oleh para progremer, dan software sudah ada secara perkembangan berbagai tipe aplikasi, mulalui dari aplikasi console, aplikasi desktop, game,dan applet (aplikasi yang berjalan di lingkungan web browser), aplikasi-aplikasi yang berskala enterprise. Untuk memudahkan kebutuhan tipe aplikasi yang beragam macam tersebut, Java dikategorikan menjadi tiga edisi, yaitu: J2SE (Java 2 Platform Standart Edition) untuk membuat aplikasi-aplikasi desktop dan apllet, J2EE (Java 2 Platform Enterprise Edition) untuk membuat aplikasi-aplikasi multitier berskala enterprise, dan J2ME (Java 2 platform Micro Edition) untuk membuat aplikasi aplikasi yang dapat dijalankan dilingkungan perangkat-perangkat mikro seperti handphone, PDA dan Smartphone.

Eclipse
Eclipse adalah sebuah IDE (Integrated Develironmenopment Envt) untuk mengembangkan perangkat lunak dan dapat dijalankan di semua platform (platform independent). Berikut ini adalah sifat dari Eclipse: a. Multi-platform : Target sistem operasi Eclipse adalah Microsoft Windows, Linux, Solaris, AIX, HP-UX dan Mac OS X.

b. Muliti-language : Eclipse dikembangkan dengan bahasa pemrograman Java, akan tetapi Eclipse mendukung pengembangan aplikasi berbasis bahasa pemrograman lainnya, seperti $C / C++$, Cobol, Python, Perl, PHP, dan lain sebagainya.

c. Multi-role : Selain sebagai IDE untuk pengembangan aplikasi, Eclipse pun bisa digunakan untuk aktivitas dalam siklus pengembangan perangkat lunak, seperti dokumentasi, test perangkat lunak, pengembangan web, dan lain sebagainya.

Eclipse pada saat ini merupakan salah satu IDE favorit dikarenakan gratis dan open source, yang berarti setiap orang boleh melihat kode pemrograman perangkat lunak ini. Selain itu, kelebihan dari Eclipse yang membuatnya populer adalah kemampuannya untuk dapat dikembangkan oleh pengguna dengan komponen yang dinamakan plugin. Pada IDE Eclipse sedangkan database aplikasi diletakkan di localhost komputer. Setelah pengujian di emulator berhasil, maka aplikasi akan diInstal di hanpone. Selanjutnya, database aplikasi akan di letakkan di web sever supaya dapat diakses melalui jaringan internet.

\section{Adobe Photoshop}

Aplikasi adobe photoshop adalah program komputer yang merupakan perangkat lunak atau software yang di gunakan untuk pengolahan gambar/foto, dapat di gunakan untuk memanipulasi foto sehingga hasil foto lebih menarik. Suyati, (2008 : 1) Aplikasi Adobe Photoshop pada dasarnya merupakan aplikasi pengolah gambar, namun seringkali pula ia digunakan untuk mengubah tampilan suatu objek, misalnya teks atau tulisan. Adobe 
Photoshop bukan pengolah kata, tapi ia dapat membuat beragam efek menarik untuk mempercantik tampilan gambar dan teks. Kaeruddin, (2005 : 13) Aplikasi program adobe photoshop adalah program yang berorientasikan untuk mengedit, memodifikasi, maupun memanipulasi gambar atau foto, pengaturan warna yang semakin akurat, penggunaan fasilitas efek dan filter yang semakin canggih, dan fasilitas pemodifikasian tipografi teks yang semakin unuk dan fantastik. Agung, (2011 : 2) Adobe Photoshop adalah salah satu sofware untuk mengolah foto ataupun gambar, dengan adobe photoshop kita dapat memperbaiki dan mempercantik foto yang ingin kita cetak dengan menambahkan efek dalam foto tersebut, sehingga foto yang biasa menjadi sebuah foto dengan tampilan yang berbeda dan menarik.

Kelebihan dari Adobe Photoshop:

1. Membuat tulisan dengan effect tertentu.

2. Membuat tekstur dan material yang beragam.

3. Mengedit foto dan gambar yang sudah ada.

4. Memproses materi Web. Sedangkan kelemahan dari Adobe Photoshop dalam menciptakan Image adalah bahwa Adobe Photoshop hanya bisa digunakan untuk menciptakan Image yang statis, dan juga dengan berkembangnya versi Photoshop sekarang ini spesifikasi Komputer untuk menjalankan program Adobe Photoshop juga harus sudah tinggi dan yang pasti akan diimbangi oleh harga yang tinggi pula. Dasar dari teori editing adalah ketika seseorang melihat satu shot atau gambar dan berlanjut ke shot lainya, secara alamiah akan menghubungkan atau ber asosiasi menjadi rangkaian yang utuh. Inilah dasar sederhana dari teori editing. Editing foto adalah merencanakan dan memilih serta menggabungkan kembali potongan gambar yang diambil para editor untuk disiarkan dalam bentuk modifikasi gambar (Nardi 2011: 47)

\section{UML (Unified Modeling Language)}

Unified Modeling Language (UML) adalah sebuah "bahasa" yang telah menjadi standar dalam industri untuk visualisasi, merancang dan mendokumentasikan sistem perangkat lunak. UML menawarkan sebuah sistem. Dengan menggunakan $U M L$ dapat dibuat model untuk semua jenis aplikasi perangkata lunak, dimana aplikasi tersebut dapat berjalan pada, sistem operasi dan jaringan apapun, serta ditulis dalam bahasa pemrograman. Tetapi karena $U M L$ juga menggunakan cllass dan operation dalam konsep dasarnya, maka lebih cocok untuk penulisan piranti lunak dalam bahasa berorientasi objek seperti $C^{++}$, Java, atau VB. NET (Hariman 2002).

\section{DIAGRAM UML}

Setiap sistem yang kompleks seharusnya bisa dipandang dari sudut yang berbeda-beda sehingga bisa mendapatkan pemahaman secara menyeluruh. Untuk upaya tersebut $U M L$ menyediakan 9 jenis diagram yang dapat dikelompokkan berdasarkan sifatnya statis atau dinamis. Ke 9 diagram dalam $U M L$ itu adalah :

1. Diagram Kelas

Diagram kelas bersifat statis. Diagram ini memperlihatkan himpunan kelas-kelas, antarmuka, kolaborasi-kolaborasi, serta relasi.

2. Diagram Objek

Diagram objek bersifat statis. Diagram ini memperlihatkan objek - objek serta relasi antar objek. Diagram objek memperlihatkan instansiasi statis dari segala sesuatu yang dijumpai pada diagram kelas.

3. Use Case Diagram

Diagram ini bersifat statis. Diagram ini memperlihatkan himpunan use case dan aktor-aktor (suatu jenis khusus dari kelas). Diagram ini sangat penting untuk mengorganisasi dan memodelkan perilaku dari suatu sistem yang dibutuhkan serta diharapkan pengguna.

4. Sequence Diagram (Diagram urutan)

Diagram ini bersifat dinamis. Diagram sequence merupakan diagram interaksi yang menekankan pada pengiriman pesan (message) dalam suatu waktu tertentu.

5. Collaboration Diagram

Diagram ini bersifat dinamis. Diagram kolaborasi adalah diagram interaksi yang menekankan organisasi struktural dari objek - objek yang menerima serta mengirim pesan (message).

6. Statechart Diagram

Diagram ini bersifat dinamis. Diagram ini memperlihatkan state-state pada sistem, memuat state, transisi, event, serta aktifitas. Diagram ini penting untuk memperlihatkan sifat dinamis dari antarmuka, kelas, kolaborasi dan terutama penting pada pemodelan sistemsistem yang reaktif.

7. Acitivity Diagram

Diagram ini bersifat dinamis. Diagram ini adalah tipe khusus dari diagram state yang memperlihatkan aliran dari suatu aktifitas ke aktifitas lainnya dari suatu sistem. Diagram ini tekanan pada penting dalam pemodelan fungsi - fungsi suatu sistem dan memberi aliran kendali antar objek.

8. Component Diagram

Diagram ini bersifat statis. Diagram ini memperlihatkan organisasi serta kebergantungan pada komponen komponen yang telah ada sebelumnya. Diagram ini berhubungan dengan diagram kelas dimana komponen secara tipikal dipetakan ke dalam satu atau lebih kelas kelas, antarmuka - antarmuka, serta kolaborasi kolaborasi.

9. Deployment Diagram

Diagram ini bersifat statis. Diagram ini memperlihatkan konfigurasi saat aplikasi dijalankan (run time). Dengan ini memuat simpul - simpul (node) beserta komponen komponen yang ada di dalamnya. Deployment diagram berhubungan erat dengan diagram memuat satu atau lebih komponen - komponen. Diagram ini sangat 
berguna saat aplikasi berlaku sebagai aplikasi yang dijalankan pada banyak mesin (distributed computing).

\section{METODOLOGI PENELITIAN}

\section{Lokasi Penelitian}

Penelitian dilakukan di kampus Politeknik Gorontalo di Jl Muchils rahim di Desa Panggulo Kecamatan Botupingge Kabupaten Bone Bulango.

\section{Waktu Penelitian}

Penulis melakukan penelitian sejak bulan November 2015 - Januari 2016.

\section{Metode Pengumpulan Data}

Sampel dua orang tunrungu dan tunawicara mengunakan kamus bahasa isyarat dalam pengumpulan data.

\section{Observasi}

Mengamati secara langsung mengenai bahasa isyarat,dan mengalami ganguan mengungkapkan apa yang di pikirkan, dengan kata lain penderita hanya bisa mengungkapakan kata lewat isyarat atau memancing perhatian pada orang-orang di sekelilingnya.

\section{Wawancara}

Wawancara secara langsung ke Mahasiswa yang sudah mengetahui bahasa isyarat yang tidak mengalami gangguan karena mengetahui bahasa isyarat, pengumpulan data ini di lakukan di politeknik Gorontalo.

\section{Alur Sistem Berjalan}

Bahasa Isyarat di Kampus Politeknik Gorontalo selama ini masih membutuhkan pendidikan yang bisa memahami bahasa isyarat tunarungu dan tunawicara.

\section{Use Case system yang diusulkan}

\section{Use Case}

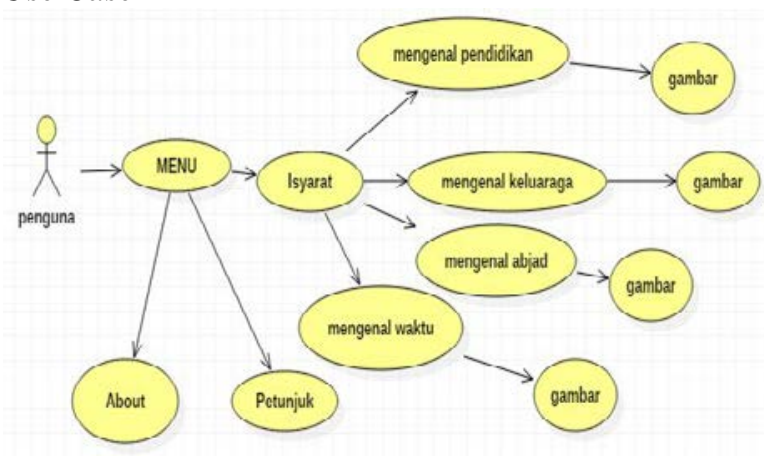

Gambar 1. Alur sistem yang diusulkan.

a. Halaman Tentang Menu

Pengunaan menu adalah mengenai bahasa isyarat tentang menu pertama yang dijalankan dan akan muncul tampilan seperti pada gambar di bawah ini mengenai bahasa isyarat.

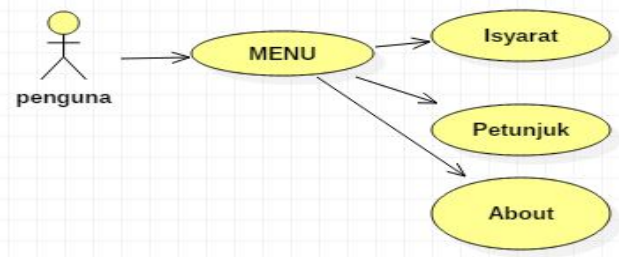

Gambar 2. Alur menu pilihan

b. Halaman Menu Bahasa Isyarat

Halaman menu isyarat adalah yang terdiri pilihanpilihan menu utama yang akan tampil di dalam project,pertama akan tampilan yaitu:

1). Pendidikan akan muncul cllass tampilan gambar

2). Hubungan keluarga akan tampilan cllass gambar

3). Hari ini , tampilan cllass gambar bisa bergerak

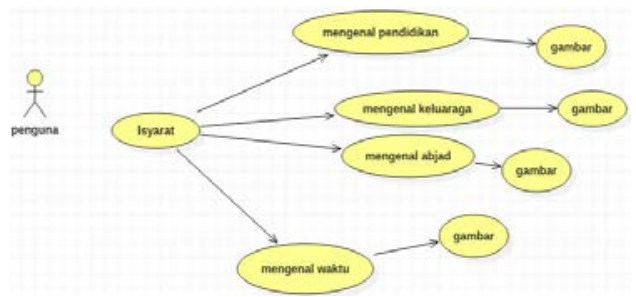

Gambar 3. Pilihan menu isyarat

c. Halaman Menu Petunjuk Aplikasi

Menu petunjuk adalah cara untuk mengunakan aplikasi bahasa isyarat,agar aplikasi bisa berjalan dengan secara baik.

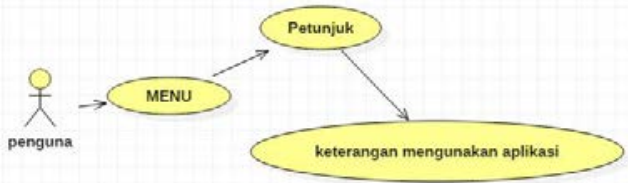

Gambar 4. Tampilan Menu Petunjuk apalikasi

\section{d. Halaman About}

Halaman about adalah mengenai tentang tampilan gambar foto yang kita simpan di dalam aplikasi bahasa isyarat.

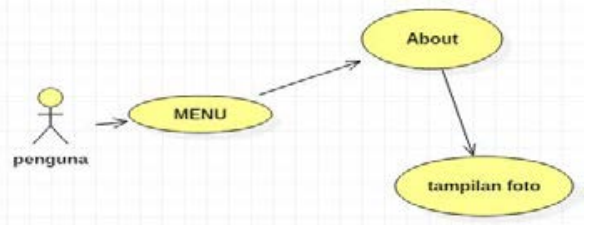

Gmabar 5. Tampilan Menu About 


\section{Desain Aplikasi}

Tampilan Dasian Aplikasi.

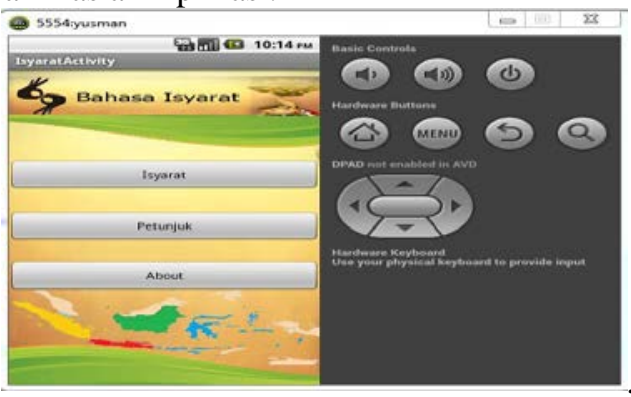

Gmabar 6. Tampilan Desain MenuUtama.

\section{IMPLEMENTASI}

Setelah aplikasi dan didesain secara rinci, maka selanjutnya kita masuk perancangan aplikasi yang di buat pada bab sebelumnya. Pada tahap implementasi ini dapat meliahat bagaimana aplikasi yang di jalankan, tahap implemantasi ini bertujuan untuk mengkonfirmasi modulmodul perancangan sehingga pengguna dapat memberikan masukkan kepada pembuat aplikasi.

\section{Tampilan Menu Utama}

Berikut ini adalah tampilan menu utama, di dalam tampilan ini menyediakan beberapa pilihan Menu yaitu Menu Isyarat, Menu Petunjuk Aplikasi, Menu About.

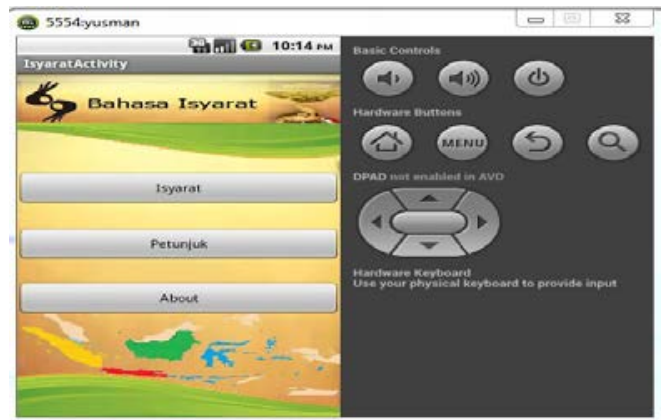

Gambar 7. Tampilan Menu Utama.

\section{Menu Isyarat}

Berikut ini adalah tampilan Menu Isyarat, ada beberapa pilihan di dalam tampilan Menu Isyarat, Mengenal Pendidikan, Mengenal Keluarga, Mengenal Waktu seperti pada gambar 4.3 .

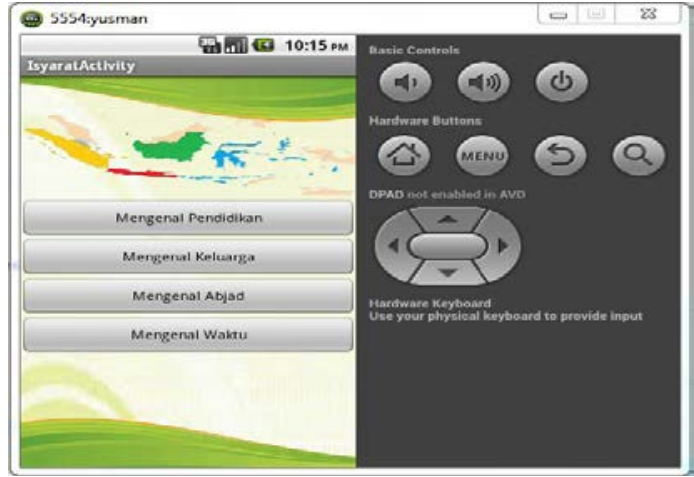

Gamabar 8. Tampilan Menu Isyarat.

Tampilan Mengenal Cllass Pendidikan.

Berikut ini adalah mengenai tampilan layout mengenal pendidikan, di dalam tampilan layout ada beberapa nama-nama cllass Activity, jika salah satunya button huruf di klik akan muncul gambar, selanjutnya penguna menyentuh layar maka gambar akan bergerak mengeluarkan suara yang bahasa isyarat.

Tampilan layout cllass belajar.

Berikut ini tampilan layout cllass belajar, ketika penguna mengklik button belajar maka akan muncul tampilan gambar bergerak mengunakan isyarat.

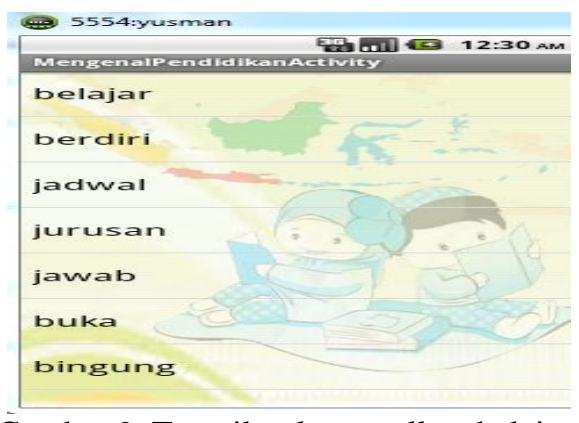

Gambar 9. Tampilan layout cllass belajar.

Tampilan hasil gambar bergerak.

Berikut ini tampilan layout ketika penguna menyentu button belajar maka tampilan gambar akan bergerak mengunakan isyarat.

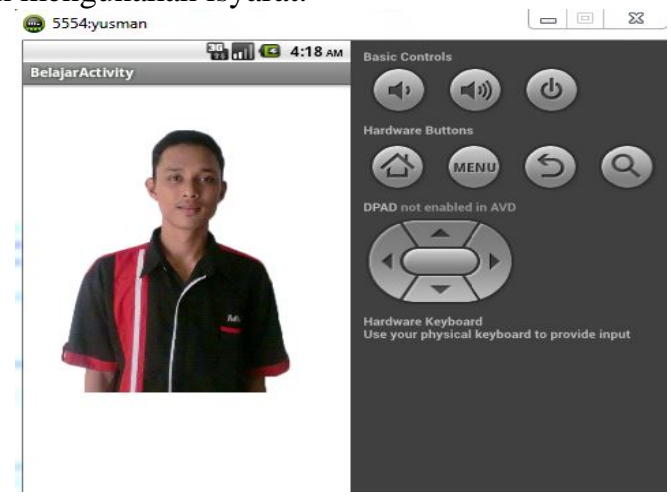

Gambar 10. Tampilan layout belajar. 


\section{Tampilan Mengenal Class Keluarga.}

Berikut ini adalah mengenai tampilan layout mengenal keluarga, di dalam tampilan layout ada beberapa nama-nama cllass Activity, jika salah satunya button huruf di tekan akan muncul gambar, selanjutnya penguna menyentuh layar maka gambar akan bergerak mengeluarkan suara sesuai kata yang dipilih.

Tampilan layout class ayah.

Berikut ini tampilan layout cllass ayah, ketika penguna mengklik button Ayah maka akan muncul tampilan gambar bergerak mengunakan isyarat.

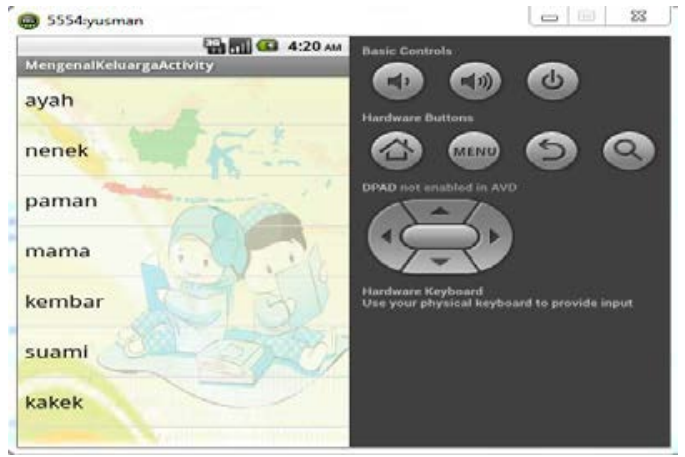

Gambar 11. Tampilan layout cllass ayah.

Tampilan hasil gambar bergerak.

Berikut ini tampilan layout ketika penguna mengklik button ayah maka tampilan gambar akan bergerak mengunakan isyarat.

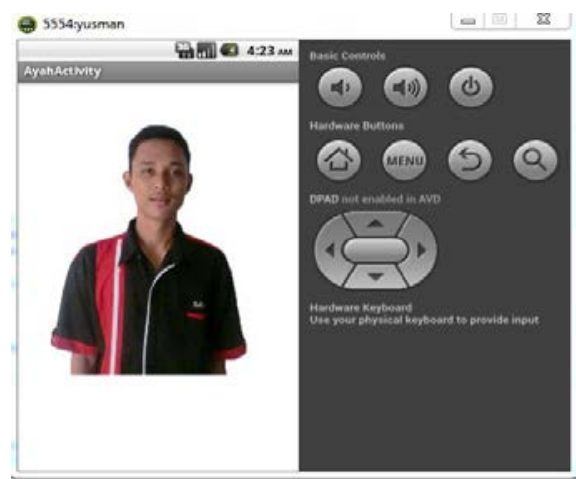

Gambar 12. Tampilan layout Ayah.

Tampilan Mengenal Button Class Abjad.

Berikut ini adalah mengenai tampilan layout mengenal abjad, di dalam tampilan layout ada beberapa nama-nama cllas Activity, jika salah satunya button huruf di mengklik akan muncul gambar, selanjutnya penguna menyentuh layar maka gambar akan bergerak mengeluarkan suara yang bahasa isyarat.

Tampilan layout class A.

Gambar 4.5 merupakan tampilan layout cllass A, ketika penguna mengklik button huruf A maka akan muncul tampilan gambar bergerak mengunakan isyarat.

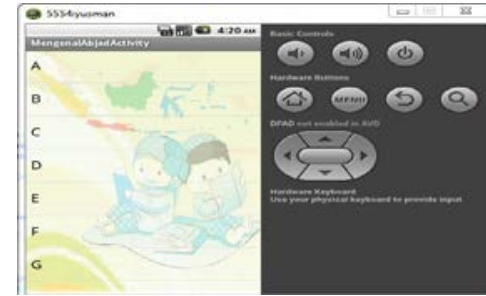

Gambar 13. Tampilan layout A.

Tampilan hasil gambar bergerak.

Berikut ini tampilan layout ketika penguna mengklik button A maka tampilan gambar akan bergerak mengunakan isyarat.

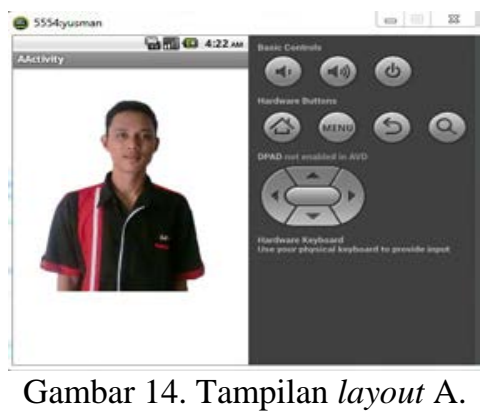

\section{Tampilan Mengenal Button Class Waktu.}

Berikut ini adalah mengenai tampilan layout mengenal waktu, di dalam tampilan dilayout ada beberapa nama-nama cllass Activity, jika salah satunya button huruf di klik akan muncul gambar, selanjutnya penguna menyentuh layar maka gambar akan bergerak mengeluarkan suara yang bahasa isyarat.

Tampilan layout cllas Minggu.

Berikut ini tampilan layout cllas Minggu, ketika penguna mengklik button huruf Minggu maka akan muncul tampilan gambar bergerak mengunakan isyarat.

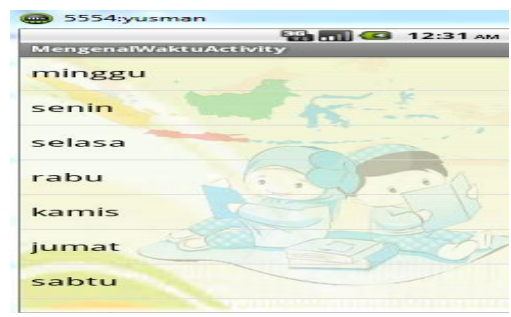

Gambar 15. Tampilan layout Minggu.

Tampilan hasil gambar bergerak. mengklik button Minggu maka tampilan gambar akan bergerak mengunakan isyarat. 


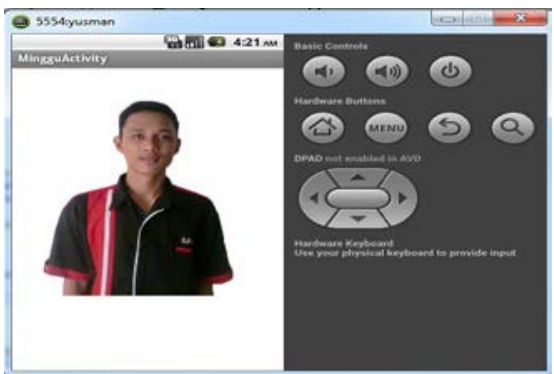

Gambar 16. Tampilan layout Minggu.

\section{Kesimpulan}

\section{PENUTUP}

Kesimpulan dari penelitian Proyek Akhir yang berjudul : "Aplikasi Bahasa Isyarat Sederhana Berbasis Android" adalah sebagai berikut :

1. Aplikasi ini dapat memperkenalkan bahasa isyarat tuna rungu dan tuna wicara kepada penguna Ponsel Android.

2. Aplikasi ini di bangun untuk mengunakan bahasa isyarat, agar di mengerti oleh Mahasiswa maupun dosen.

\section{Saran}

Dalam membangun aplikasi bahasa isyarat berbasis Ponsel Android ini masih belum sempurna dan masih banyak kekurangannya. Oleh karena itu perlu dikembangkan dan penyempurnaan lebih lanjut. Adapun saran agar aplikasi ini lebih menarik adalah aplikasi ini ditambahkan gerakan bahasa isyarat yang ketika disentuh akan mengeluarkan suara, oleh sebab itu kedepannya dapat diberikan fitur gerakan isyarat.

\section{DAFTAR PUSTAKA}

[1] A Hariman, A.S.,(2002), "Visual Modelling menggunakan UML dan Rational Rose", Penerbit Informatika Bandung.

[2] Khaeruddin. (2005). Belajar Otodidak Adobe Photoshop CS. Bandung : CV. Yrama Widya.

[3] M. Leo Agung, (2011). Element 9 Untuk Pemula. Yogyakarta : Andi Yogyakarta.

[4] Mulyadi, ST. (2010), Membuat Aplikasi Android, Multimedia Center Publishing, Yogyakarta.

[5] Pratama ,Widianto. 2011. Tutorial Android Programing.

[6] Utomo Priyo Eko, 2009, Panduan Mudah Mengenal Bahasa Java, CV Yrama Widya, Bandung. 